\title{
Инвестиционная революция в тепле. Рубцовская модель
}

Е.А. КосоговА, директор по тарифообразованию ООО «Сибирская генерирующая компания», Москва

Аннотация. Текст основан на выступлении Е. А. Косоговой в рамках круглого стола «Реформирование российской тепло- и электроэнергетики: итоги, текущие проблемы и вызовы», прошедшем 30 мая 2019 г. в Институте экономики и организации промышленного производства СО РАН. ООО «Сибирская генерирующая компания» в 2016-2017 гг. провела комплексную реконструкцию системы теплоснабжения г. Рубцовска (Алтайский край), включая модернизацию магистральных тепловых сетей, генерирующего оборудования Южной тепловой станции. Е. А. Косогова рассказала об особенностях организации и финансирования этого проекта, вскрывшихся в ходе его реализации проблемах и найденных механизмах их разрешения.

Ключевые слова: теплоснабжение; тепловые сети; ТЭЦ; Рубцовск; Алтайский край; Сибирская генерирующая компания; тариф на теплоэнергию

000 «Сибирская генерирующая компания» была образована в 2009 г. на базе энергетических активов Сибирской угольной энергетической компании (СУЭК). Сегодня она владеет активами на территории Алтайского и Красноярского краев, Кузбасса, Новосибирской области, республик Хакасия и Тува. Общая установленная электрическая мощность ее энергостанций составляет 10,9 ГВт, тепловая - 23,9 тыс. Гкал/ч. Помимо этого, в состав группы входят тепловые сети протяженностью около 10 тыс. км, ремонтные и сервисные компании.

- Как показал наш многолетний опыт, в условиях действующего тарифного законодательства инвестору вкладывать средства в развитие отрасли бессмысленно. Прежде всего, из-за существующей практики установления предельных ограничений на рост тарифа. Если органы регулирования и позволят вам повысить инвестиционную составляющую в тарифе, они урежут все остальное, обосновывая это необходимостью выдерживать предельный индекс роста платы для граждан. Достаточно посмотреть судебные иски по спорам о тарифах, чтобы убедиться, что повсеместно распространена практика, когда органы регулирования не учитывают в тарифах обязательные расходы, установленные законодательством, включая, например, местные налоги или арендную плату за землю, хотя фактически это те средства, 
которые поступают в бюджеты муниципальных образований и субъектов Федерации.

Есть и обратная ситуация. В крупных городах, таких как Новосибирск, одновременно существуют одна или несколько единых теплоснабжающих организаций (ЕTO) и большое количество ведомственных (корпоративных) котельных. Согласно действующему законодательству, ЕТО, с одной стороны, обязаны предоставлять всем своим потребителям тепло по единым тарифам, с другой - часть этого тепла им приходится покупать у мелких котельных, включенных в единую систему теплоснабжения. Очень часто баланс цен при этом складывается не в пользу ЕТО. Например, у большинства котельных, которые работают на территории Новосибирской области, сейчас тариф выше расчетной «альтернативной котельной» $(2800 \text { руб./кВт) })^{1}$. Фактически это говорит о том, что уже сегодня гораздо выгоднее построить вместо них новую котельную, либо перевести потребителей на централизованное теплоснабжение. Но к этому постоянно возникают препоны: собственники этих котельных хотят и дальше продавать свое тепло ЕТО по 3000-4000 руб., чтобы последняя перепродавала ее всем остальным по 1100 руб. С точки зрения потребителей, эта система выглядит справедливой (жители одного города/поселка должны получать тепло по равной цене), но с точки зрения экономической и энергетической эффективности она противоречит здравому смыслу.

Что же было в Рубцовске? До 2016 г. у Сибирской генерирующей компании, если говорить откровенно, особых интересов в этом городе не было. Мы просто поставляли топливо на местные теплоисточники. Один из них (Рубцовская ТЭЦ) в свое время строился для снабжения паром Алтайского тракторного завода и отвечал за теплоснабжение 60\% города, другой (котельная Южной теплостанции (ЮТС)) в советское время был частью завода «Алтайсельмаш». После закрытия промышленных предприятий основным потребителем тепла и электроэнергии,

1 Напомним, что в соответствии с последними поправками к закону «О теплоснабжении» (№ 279-Ф3) предполагается переход к модели ценообразования на основе «альтернативной котельной», когда предельный размер тарифа устанавливается на уровне цены виртуальной «альтернативной котельной» (которая могла бы быть построена в данном населенном пункте при соблюдении заданных параметров мощности, качества работы, срока окупаемости и т.д.). 
вырабатываемых этими станциями, стало местное население. Собственники у них были разные. Рубцовская ТЭЦ управлялась ООО ИДК (Инвестиционно-девелоперская компания), котельная ЮТС была передана муниципалитету и входила в МУП «Рубцовские тепловые сети».

Казалось бы, идеальная ситуация в городе с точки зрения создания конкуренции и надежности энергоснабжения - два источника генерации, один из которых имеет достаточную мощность для обеспечения всего города (резерв тепловой мощности в два раза превышал текущую нагрузку). Правда, зоны деятельности этих источников не были связаны.

Я похожую картину наблюдала в одном из прибалтийских городов: там в одной сети работают три источника, и потребители закупают энергию у того, кто продает дешевле. Система закольцована, тарифное регулирование очень либеральное, налицо чистая конкуренция, которая, как считается, стимулирует рост эффективности. Но мы же понимаем: за то, что почти всегда одна ТЭЦ стоит и не работает, кому-то приходится платить. Ведь постоянные расходы у этой ТЭЦ остаются в любом случае: заработная плата, налоги, амортизация... Нетрудно догадаться, что так или иначе за все это платит потребитель.

В Рубцовске поддержание такой вот вынужденной конкуренции обернулось для населения непосильной ношей. Тарифы в черте города различались в полтора раза: по состоянию на 2016 г. в северной части города (зона ответственности Рубцовской ТЭЦ) потребители платили 1547 руб./Гкал, в южной 1566 , а в западной - 2248 руб. (обе обслуживались ЮТС). При этом - важная особенность - контуры, по которым теплоноситель доставляется до потребителей, в Рубцовске были замкнуты, перемычки между ними не было, так что в действительности одна станция не могла подменить другую, скажем, в случае аварии, и реальной ценовой конкуренции тоже не было 2.

\footnotetext{
${ }^{2}$ По информации «ЭКО», обе теплоснабжающие организации Рубцовска неоднократно жаловались на заниженные тарифы, и даже пытались судиться по этому поводу с мэрией города. Так, МУП «Рубцовские тепловые сети» оценило свои убытки от заниженных тарифов в 2009-2015 гг. в 610 млн руб. URL: https:/altapress.ru/ekonomika/story/ kommunalshchiki-bankroti-trebuyut-ot-merii-rubtsovska-bolshe-polovini-gorodskogobyudzheta-209297
} 
В результате обе теплоснабжающие организации оказались в предбанкротном состоянии: у ИДК размер кредиторской задолженности достиг 500 млн руб., у ЮТС - 300, все вместе это составляет почти половину бюджета города. Источников, чтобы погасить эти долги, в городе объективно не существует, так что фактически выход у обоих предприятий был один - банкротство. Про износ оборудования уже говорить не приходится - можно догадаться, в каком состоянии находились турбогенераторы, котлы, тепловые сети, построенные еще в советское время и эксплуатировавшиеся с нарушениями...

Рубцовск - третий по величине город Алтайского края. Численность населения - 146000 человек, бюджет города на 2019 г. - 1,7 млрд руб. (дефицит - 52 млн руб.). Средняя продолжительность отопительного сезона - 206 дней. По состоянию на 2015 г. система теплоснабжения города включала 1) 000 ИДК Рубцовская ТЭЦ (установленная тепловая мощность - 245 Гкал/ч, износ основного оборудования - 100\%); 2) МУП Рубцовские тепловые сети, в составе Южной теплостанции, малых котельных, сетевого хозяйства (установленная мощность ЮТС 267 Гкал/ч, износ оборудования - 60\%, износ теплосетей $85 \%$, потери в сетях - более $50 \%$ ).

При таком финансовом положении теплоснабжающих организаций, ужасающем состоянии оборудования, теплосетей город в течение многих лет испытывал серьезные проблемы с теплоснабжением. В январе 2005 г., когда температура в квартирах и домах половины жителей опустилась до 4-6 градусов, в городе был объявлен режим чрезвычайной ситуации, зимой 2011 г. температура в нескольких сотнях квартир опустилась до 8-12 градусов, в 2014 г. Ростехнадзор выдал предписание о невозможности дальнейшей эксплуатации Рубцовской ТЭЦ. В ноябре 2015 г. администрация Алтайского края обратилась в Сибирскую генерирующую компанию.

Мы к тому времени уже имели положительный опыт работы в регионе, в том числе - в 2011-2014 гг. провели масштабную реконструкцию Барнаульской ТЭЦ-2 - в рамках договоров предоставления мощности (ДПМ). По приглашению администрации края мы провели аудит системы теплоснабжения Рубцовска и предложили проект реконструкции. Основная идея заключалась в том, чтобы объединить оба контура, построив перемычку, и вывести из схемы теплоснабжения Рубцовскую ТЭЦ, ремонтировать которую уже не было смысла (проще взорвать).

Естественно, нам нужны были гарантии возврата инвестиций. К тому времени закон об «альтернативной котельной» уже был 
разработан (при нашем непосредственном участии), и механизм инвестирования нас в принципе вполне устраивал, но времени ждать, когда г. Рубцовск будет отнесен к ценовой зоне, у нас не было, вкладывать нужно было уже «вчера». Поэтому мы утвердили тариф методом RAB-регулирования ${ }^{3}$ - в отдельно взятом муниципалитете на отдельно взятом отрезке теплосети (строительство перемычки между контурами), под объем инвестиций в 300 млн руб. Это был первый случай в России, когда этот метод применялся не в электро-, а в теплосетевом хозяйстве. Регулирующие органы и Алтайский край пошли нам навстречу, они понимали, что мы страхуемся. Теперь уже необходимость в RAB-регулировании отпала, потому что Рубцовск перешел на метод альтернативной котельной.

Что при этом происходило с тарифом? До 2016 г. в разных частях города существовал свой тариф, поскольку источники были разные. Мы эти тарифы в 2017 г. объединили сначала на уровне 1546 руб., а к концу года подняли его до 1993 руб. При этом у части населения цены заметно упали, а у другой - поднялись. В 2018 г. мы этот опыт повторили в Барнауле и в ближайшем будущем планируем сделать то же самое в Бийске.

Возможно, это кому-то покажется несправедливым. С одной стороны, если человек живет рядом с ТЭЦ, он не должен оплачивать работу сетей, и у него должен быть тариф с коллекторов. С другой - вряд ли правильно, если в одном и том же населенном пункте тарифы различаются в полтора-два раза, так что у части населения тариф даже выше альтернативной котельной. Но это отдельная тематика, а здесь хотелось бы просто рассказать о том практическом опыте, который у нас есть.

Так как по плану уже к июню 2017 г. вместо двух теплоисточников должен был остаться один, мы считаем, что «замес» тарифов был произведен абсолютно объективно. Да, рост в течение года на $25 \%$ - это тяжело. Я сама ездила на собрания жителей

\footnotetext{
${ }^{3} \mathrm{RAB}$ (Regulatory Asset Base - регулируемая база инвестированного капитала) - это система долгосрочного тарифообразования, используемая для привлечения инвестиций в расширение и модернизацию инфраструктурных объектов. В России применяется в основном в электросетевом хозяйстве. Порядок расчетов прописан в «Основах ценообразования в сфере теплоснабжения», утвержденных постановлением Правительства РФ от 22.10.2012 № 1075 и «Методических указаниях по расчету регулируемых цен (тарифов) в сфере теплоснабжения», утвержденных приказом ФСТ России от 13.06.2013 № 760-э.
} 
г. Рубцовска. На них бывало до 400 человек, в основном это были женщины «в возрасте». Все проходило очень эмоционально со слезами. Но все-таки, пережив несколько очень тяжелых зим, они прекрасно понимали, что платить надо, потому что другого выхода нет...

Как мы рассчитывали размер тарифа? Не от цены альтернативной котельной. И не по затратам, потому что затраты в отдельно взятый год не показательны. Мы считали обратным путем: оценили вложения, которые необходимо сделать, чтобы привести систему в порядок, текущие затраты (топливо, заработная плата, текущие ремонты, налоги), стоимость возврата капитала (сколько мы должны заплатить банку), и на этой основе определили общую сумму выручки, необходимой, чтобы покрыть эти расходы в течение 10 лет. У нас есть для этого модельные таблицы. Далее делим эту выручку на полезный отпуск и получаем уровень тарифа.

Сразу скажу, что по текущему регулированию (до вхождения Рубцовска в ценовую зону и принятия модели альтернативной котельной) нам бы пришлось заложить 2 млрд руб. инвестиций в тариф на первые два года, что население вряд бы потянуло. При этом после закрытия одного из источников (а это, напомню, отдельное юрлицо), мы не смогли бы переложить его расходы на второй. А это, кроме прочего, означает, что при увеличении расходов, полезного отпуска тариф у второго источника остался бы на прежнем уровне (в текущем регулировании). Поэтому до перехода города на модель альтернативной котельной мы не хотели туда заходить. Текущее регулирование, еще раз повторю, не способствует вложению инвестиций в отрасль...

Что Сибирская генерирующая компания сделала в городе? Первым делом (сентябрь 2016-октябрь 2017 г.) мы переложили магистральные теплопроводы на другие диаметры труб, чтобы увеличить пропускную способность, и в феврале-сентябре 2017 г. построили перемычку между Южным и Северным контурами. Только в сетевое хозяйство за первый год было вложено около миллиарда рублей. В течение двух лет мы буквально перекопали весь город. Ни ходить, ни ездить там было невозможно. Тем не менее за два сезона мы эту работу завершили.

Далее стояла задача повысить мощность Южной теплостанции. Здесь были установлены два водогрейных котла с общей мощностью 60 Гкал/ч (апрель-октябрь 2017 г.) и турбогенератор 
мощностью 6 МВт для обеспечения собственных нужд (январь 2019 г.), то есть фактически мы превратили котельную в ТЭЦ.

Общая сумма всех инвестиций за три года превысила 2,1 млрд руб. При этом годовая выручка в Рубцовске у нас составляет около 1 млрд руб., и в основе нашей договоренности с населением была гарантия соблюдения предельного индекса цен. Первоначально мы планировали вернуть денежные средства за 10 лет, и на этот срок заключили договор концессии с регионом. Но когда раскопали теплосети, выяснилось, что из-за грунтовых вод и сроки, и стоимость работ значительно возрастают, и в первоначальный график мы не укладываемся. Фактически мы не сможем окупить свои вложения даже за 12 лет. Поэтому было принято решение по истечении 10 лет продлить концессию и применить метод альтернативной котельной еще на 10 лет. Тем более что мы уже видим, что потребуются дополнительные инвестиции: необходимо провести техническое перевооружение малых котельных, на Южной теплостанции обновить часть оборудования, продолжить работы по реконструкции теплосетей.

Что мы имеем в Рубцовске на данный момент? Проблема с теплоснабжением решена - зимой в домах поддерживается температура 20-24 градуса, подача горячей воды в летний период прекращается максимум на 2-3 недели (раньше-на все лето). Мы не только переложили сети, но и восстановили благоустройство после себя: построили детские площадки, места отдыха горожан, заасфальтировали улицы.

Улучшилась экономика предприятия: коэффициент использования мощности вырос в два раза, потери энергии при передаче снижены с $40 \%$ до $30 \%$, и мы продолжаем над этим работать; утечки теплоносителей снижены на 17\%, проблем в течение отопительного периода не было. Планируем довести сверхнормативные потери хотя бы до $14 \%$, летнее отключение горячей воды сократить до одной недели.

Но появились проблемы, которых мы не могли предвидеть, когда брались за этот проект. Получив - впервые за многие годы - нормальное теплоснабжение, жители города решили, что теперь они должны не только тепло, но и горячую воду получать хорошего качества, и... пошли в суды. Наша инвестиционная программа в принципе предусматривает модернизацию горячего водоснабжения, но не так быстро. Основная проблема связана 
с тем, что все схемы в городе тупиковые, и теплоноситель просто остывает в трубах. Требуется очень масштабная модернизация сети, которая, по нашей оценке, будет стоить не меньше миллиарда рублей. Это не вписывается в текущие тарифы, по которым рассчитываются с нами рубцовчане, поэтому мы пытаемся для решения этой проблемы привлечь бюджетное финансирование работаем с Минстроем и с администрацией края для разработки совместной программы с Фондом содействия развитию ЖКХ.

Однако эти аргументы потребители не слышат и ждать не хотят. Помимо потребителей в суды пошли Роспотребнадзор, Ростехнадзор, которые там годами не появлялись, пока не было собственника «с деньгами», пришла прокуратура со всеми проверками. В целом, проблема такова: пока муниципалитет и хозяйствующие субъекты, с которых нечего взять, разваливают систему теплоснабжения, никто ничего не предпринимает. Но как только приходит нормально функционирующая организация, тут же появляются контролирующие органы. Мы на собственном опыте убедились, что этот момент обязательно нужно учитывать в своих инвестиционных проектах. И если мы не можем довести систему до идеального состояния, то лучше вообще в это не ввязываться...

Еще один момент, который активно дискутируется в последнее время - размер предельного тарифа в ценовых зонах, перешедших на метод альтернативной котельной. По опыту Сибирской генерирующей компании могу сказать, что ни в одном из регионов присутствия мы не доводим тариф до предельного уровня, потому что на самом деле - это цена ухода потребителя от теплоснабжающей организации. Я уже вкратце рассказала, как мы считаем свои тарифы. Наша позиция в том, чтобы действующий тариф был ниже предельной цены, чтобы потребители покупали у нас, а не строили собственные источники теплоснабжения.

В целом, хочу подчеркнуть, что именно благодаря новому законодательству руководители российских муниципалитетов получили эффективный инструмент привлечения инвестиций в отрасль. Надеемся, они изучат опыт Рубцовска и примут верные решения о возможности применения нового метода тарифного регулирования в своих городах, не дожидаясь наступления негативных последствий. 


\section{Summary}

Kosogova, E.A. Director on tariffs of $O O O$ «Siberian Generating Company», Moscow

\section{Investment Revolution in Heating. The Rubtsovsk Model}

Abstract. The text is based on the presentation of E.A. Kosogova delivered during a round table discussion 'Reforming the Russian heating and electric energy generation: the results. Current problems and challenges' that took place on May, 30, 2019 in the Institute of Economics and Industrial Engineering SB RAN. In 2016-2017, OOO 'Siberian generating company' implemented an all around reconstruction of the heating system of the town of Rubtsovsk (Altai krai) including modernization of the main heating network, generating facilities of the Rubtsovsk central heating and power plant. E.A. Kosogova revealed details about peculiarities in organization and financing of this project, problems of implementation as well as ways they were resolved.

Keywords: heating; heating networks; тепловые сети; central heating and power plant, Rubtsovsk; Altai krai; Siberian generating company; heating tariffs

Для цитирования: Косогова Е.А. Инвестиционная революция в тепле. Рубцовская модель // ЭКО. 2019. № 9. C. 70-78. DOI: 10.30680/ECO0131-76522019-9-70-78.

For citation: Kosogova, E.A. (2019). Investment Revolution in Heating. The Rubtsovsk model. ECO. No. 9. Pp. 70-78. (In Russ.). DOI: 10.30680/ECO01317652-2019-9-70-78. 